\title{
Remote cutting of Li-ion battery electrodes with infrared and green ns-pulsed fibre lasers
}

\author{
Ali Gökhan Demir*, aligokhan.demir@polimi.it \\ Barbara Previtali, barbara.previtali@polimi.it \\ Department of Mechanical Engineering, Politecnico di Milano, Via La Masa 1, 20156 \\ Milan, Italy \\ *Corresponding author
}




\title{
Remote cutting of Li-ion battery electrodes with infrared and green ns-pulsed fibre lasers
}

Ali Gökhan Demir ${ }^{1 *}$, aligokhan.demir@polimi.it

Barbara Previtali ${ }^{1}$, barbara.previtali@ polimi.it

Department of Mechanical Engineering, Politecnico di Milano, Via La Masa 1, 20156 Milan, Italy

*Corresponding author

\begin{abstract}
Thin sheet anode and cathode materials made in composite structures constitute some of the most important components of a Li-ion battery. These materials are currently cut by punching technology, which shows degrading behaviour as the tool wears out. A viable option for Li-ion battery electrode manufacturing is the use of remote laser cutting. However the operation requires fulfilling both productivity and quality aspects to substitute the conventional production method. One of the most critical aspects in quality is the clearance width, which is defined as the extent of the exposed middle layer of the sandwich at the laser cut kerf. This work investigates the quality aspects of laser cutting of Li-ion electrodes when a green fiber laser source $(\lambda=532 \mathrm{~nm}$, $\tau=1 \mathrm{~ns}$ ) is used rather than the more traditional infrared (IR) fiber laser source $(\lambda=1064 \mathrm{~nm}, \tau=250 \mathrm{~ns})$. The processing conditions were investigated to reveal the technological feasibility zones. Clearance width was studied within the technological feasibility zones for all the material-laser combinations. Results showed that high productivity criterion is met by the IR system, since cutting speed could reach $30 \mathrm{~m} / \mathrm{min}$ with $54 \mathrm{~W}$ average laser power on both anode and cathode. On the other hand, the green laser provided clearance width below 20 $\mu \mathrm{m}$. In the best case the clearance on anode could be eliminated with the green laser system. Although the maximum cutting speed was $4.5 \mathrm{~m} / \mathrm{min}$, upscaling of green laser power can provide required productivity.
\end{abstract}

Keywords: Remote laser cutting; Li-ion battery; Fibre laser; Green laser; Ablation 


\begin{tabular}{|c|c|}
\hline Nomenc & clature \\
\hline A & Optical absorption \\
\hline $\mathrm{c}_{\mathrm{p}}$ & Heat capacity $[\mathrm{J} / \mathrm{kg} \cdot \mathrm{K}]$ \\
\hline $\mathrm{d}_{0}$ & Focused laser beam diameter $[\mu \mathrm{m}]$ \\
\hline $\mathrm{E}$ & Pulse energy [mJ] \\
\hline $\mathrm{L}$ & Latent heat of fusion and vaporisation $[\mathrm{J} / \mathrm{kg}]$ \\
\hline$\lambda$ & Laser wavelength [nm] \\
\hline $\mathrm{P}$ & Power [W] \\
\hline $\mathrm{P}_{\text {avg }}$ & Average power $[\mathrm{W}]$ \\
\hline $\mathrm{P}_{\text {avg, max }}$ & Maximum average laser power [W] \\
\hline PRR & Pulse repetition rate $[\mathrm{kHz}]$ \\
\hline$\rho$ & Material density $\left[\mathrm{kg} / \mathrm{m}^{3}\right]$ \\
\hline$\tau$ & Laser pulse duration $[\mathrm{ns}]$ \\
\hline $\mathrm{t}$ & Material thickness [mm] \\
\hline $\mathrm{T}_{\mathrm{v}}$ & Vaporization temperature $[\mathrm{K}]$ \\
\hline $\mathrm{T}_{0}$ & Ambient temperature $[\mathrm{K}]$ \\
\hline $\mathrm{v}$ & Scan speed $[\mathrm{m} / \mathrm{min}]$ \\
\hline $\mathrm{v}_{\text {cut }}$ & Cutting speed $[\mathrm{m} / \mathrm{min}]$ \\
\hline $\mathrm{V}_{\text {cut,lim }}$ & Limit cutting speed $[\mathrm{m} / \mathrm{min}]$ \\
\hline $\mathrm{V}_{\text {cut, } \max }$ & Maximum cutting speed $[\mathrm{m} / \mathrm{min}]$ \\
\hline $\mathrm{w}_{\mathrm{c}}$ & Clearance $[\mu \mathrm{m}]$ \\
\hline $\mathrm{w}_{\mathrm{k}}$ & Kerf width $[\mu \mathrm{m}]$ \\
\hline
\end{tabular}

\section{Introduction}

For increased mobility, high efficiency and low emission energy sources are extremely important. Hybrid vehicles, mobile devices, cellular phones and other equipment require electrical energy with increasing demand. [1]. Batteries based on Li-ion technology are crucial components for these devices allowing high energy to weight ratio [2-4]. With the increasing demand in the market for these devices, manufacturers are required to costs which are directly linked to cycle times [5]. Some of the main components of the Li-Ion batteries are anode and cathode foils, which are cut in required forms by punching. These materials consist of $\mathrm{Cu}$ sheets sandwiched between graphite layers for anode, and Al sheets sandwiched between Li metal oxide layers for cathode [4]. In punching, the process quality degrades in time due to tool wear. This eventually causes machine down times for tool repair or change, which can increase the whole process cycle time drastically. Laser remote cutting based on ablation can be adequate solution to substitute the current technology, if the cutting edge quality and productivity can be matched to punching. Moreover remote laser cutting makes use of the laser beam that is an extremely precise, weightless and no-wear tool $[6,7]$. 
High brilliance solid state lasers, with their high beam quality provide high intensity beams even with high focal lengths. This enables fast processing by scanning systems and allows processing in the absence of process gas [8]. In macro laser remote cutting applications commonly high power fibre or disc lasers are used to achieve ablation or fusion based cutting [7]. In ablation based cutting high intensity beams are required, which remove a limited extent of material with high scan speed. Single mode, multi-kW continuous wave sources are used to achieve such high intensities. Fusion cutting uses lower beam intensity by employing multi-mode light sources and a material removal mechanism based on melt repulsion by the action of the keyhole is hypothesised. In fusion cutting speeds are reduced and kerf widths are increased. Laser remote cutting process allows processing various types of materials from metallic to organic [9-13]. Regarding material thickness up to $2 \mathrm{~mm}$ can be cut by remote laser cutting on metallic materials [14].

Thin sheet cutting based on ablation is a derivate of remote laser cutting in micro applications. Although the processing speeds can be considerably lower due to used lower power levels, the process is a viable tool for thin sheet cutting [15]. More preferably pulsed solid state lasers are used, where pulse durations vary between fs to ns ranges [16-18]. Exploration of different wavelengths is also an important point to be addressed to control the laser-matter interaction better especially when multiple layered materials are concerned.

In remote laser cutting of Li-ion electrodes a common defect found in the cutting edge is the clearance. Clearance is defined as the extent of the exposed middle layer of the sandwich (i.e. $\mathrm{Cu}$ or $\mathrm{Al}$ ) at the laser cut kerf (see Fig. 1). The exposure of the middle layer is evidently problematic as it might cause short circuits in the battery. Moreover the kerf can show other irregularities such as taper on top and bottom sides as well as varying kerf width. Fig. 2 reports SEM images of non-optimized example cuts on anode and cathode materials. The images represent top side of the cuts, where clearance and kerf width are clearly visible. Moreover it can be seen that the graphite coating of $\mathrm{Cu}$ layer in anode is characterized by large particles and high amount of porosity between single particles (see Fig. 2.a). On exposed $\mathrm{Cu}$ layer the whole coating is detached. On the other hand cathode material shows smaller particles and a denser structure with less porosity (Fig. 2.b). Some of the coating material remains on the exposed Al layer after cutting. 
The amount of work available in the literature dealing with the remote cutting of Li-ion electrodes is very limited. Luetke et al [19] compared remote cutting of Li-ion electrodes with continuous wave (CW) and pulsed wave (PW) systems operating with $1 \mu \mathrm{m}$ wavelength. They showed that the CW and PW systems had similar clearance behaviour with $\mathrm{w}_{\mathrm{c}}=24-39 \mu \mathrm{m}$. Lee et al [20] studied the remote cutting of Li-ion electrodes by means of simulation and experimental investigations. The authors concluded that the copper laser cutting is a laser intensity, and interaction time dependent process, whereas the remote cutting of aluminium depends more on laser intensity than interaction time. Same authors studied the remote cutting of anode material both numerically and experimentally in another work [21]. The authors proposed a material mechanism based on sublimation for graphite coating and melting for copper. They suggested that the molten copper expels towards the graphite layer and the uneven molten copper pool reflects the laser beam over the graphite layer. These contributions can be expected to rework the graphite layer and increase clearance. The experimented anode material was coated only on one side. The obtained clearance was around $29 \mu \mathrm{m}$ with a single mode fibre laser. Schmieder [22] on the other hand studied the ablation threshold and heat affected zone characteristics of remote cut anodes as a function of pulse duration.

An important factor that requires consideration is the absorptivity of the different layers in the composite material structures in the anode and cathode materials. The more crucial parts are the middle layers in the anode and cathode. $\mathrm{Cu}$ and $\mathrm{Al}$ are known to be highly reflective to the fundamental fibre laser wavelength in infrared (IR) region $(1 \mu \mathrm{m})$. Approximately $5 \%$ of the optical power emitted in $1 \mu \mathrm{m}$ is absorbed by $\mathrm{Al}$, and the values decreases to about $2 \%$ in the case of $\mathrm{Cu}$ [23]. The second harmonic wavelength of the fibre laser, which corresponds to green wavelength $(0.5 \mu \mathrm{m})$, can increase the absorption of $\mathrm{Al}$ to around $9 \%$. For $\mathrm{Cu}$ the absorption can be increased to $>30 \%$ with the use of the green wavelength.

Therefore, two contrasting aspects require attention in the remote cutting of Li-ion electrodes: quality and productivity. As quality measure clearance should be eliminated if possible, or should be confined to remain below $20 \mu \mathrm{m}$. As a benchmark value for the industrial requirements, remote cutting should be applied at least 30 $\mathrm{m} / \mathrm{min}$ to achieve comparable productivity with punching. 
In this work remote cutting of anode and cathode multi layered materials for Li-ion battery cathodes was studied. In particular two different fibre laser systems were used. The first one used the fundamental fibre laser wavelength $(1064 \mathrm{~nm})$ and $250 \mathrm{~ns}$ pulses, while the second one employed second harmonic (532 nm) wavelength and $1 \mathrm{~ns}$ pulses. The technological feasibility limits in terms of highest cutting speed for all the material-laser combinations were investigated. A limit line as a function of laser average power against cutting speed was defined. Then the clearance of the cut kerfs on the limit line and below were investigated using designed experiments and regression analysis. The results showed that the lowest clearances lied on the limit line, and the green laser wavelength and short pulses allowed much smaller clearance. In particular, clearance on anode material was eliminated with the $532 \mathrm{~nm}, 1 \mathrm{~ns}$ system. Results were extrapolated to indicate the power requirement for the green laser system to achieve the required productivity.

\section{Materials and methods}

\subsection{Experimental setup}

Anode and cathode materials were based on thin metallic sheets sandwiched between coating layers. The anode material consisted of $10 \mu \mathrm{m}$ thick $\mathrm{Cu}$ sheets coated with graphite (total thickness: $130 \mu \mathrm{m}$ ). Cathode was formed by $15 \mu \mathrm{m}$ thick Al sheet sandwiched between two layers of Li metal oxide coating (total thickness: $120 \mu \mathrm{m}$ ).

Two laser systems operating in ns regime with IR and green wavelengths were used to cut both of the electrode materials. The IR laser system was a Q-switched fibre laser in fundamental wavelength ( $\lambda=1064 \mathrm{~nm})$ with $250 \mathrm{~ns}$ pulse duration (YLP-1/100/50/50 from IPG Photonics, Oxford, MA, USA). The IR laser source was coupled to a scanner head (TSH 8310 by Sunny Technology, Beijing, China). The scanner head was equipped with an f-theta lens with $100 \mathrm{~mm}$ focal distance (SL-1064-70-100 from Wavelength Opto-Electronic, Ronar-Smith, Singapore). The system could reach up to $360 \mathrm{~m} / \mathrm{min}$ scan speed. The laser could generate up to $54 \mathrm{~W}$ of average power and operated between $20-80 \mathrm{kHz}$ pulse repetition rate range. The green laser system was a master oscillator power amplifier (MOPA) fibre laser with second harmonic generator $(\lambda=532 \mathrm{~nm})$ and $1 \mathrm{~ns}$ pulse duration (YLPG-5 
from IPG Photonics, Oxford, MA, USA). The laser could generate up to $6 \mathrm{~W}$ of average power and pulse repetition rate ranged between $20-300 \mathrm{kHz}$. The output beam was linearly polarized, which was converted to circular polarization by means of a quarter wave plate (WPQ05M-532 Thorlabs Inc Newton, New Jersey, USA). Downstream the beam was focused with a $100 \mathrm{~mm}$ focal lens (AC254-100-A-ML from Thorlabs Inc Newton, New Jersey, USA ). The system was implemented to high precision linear axes, which manipulated the workpiece with a maximum scan speed of $30 \mathrm{~m} / \mathrm{min}$ (AI-LM-15000-XY from Alio Industries, Wheat Ridge, CO, USA). The general specifications of the two systems are listed in Table 1.

The cut quality was analysed with optical microscopy and relative measurements were taken using the dedicated software using the digital images (Leitz Ergolux 200 and Leica IM50 from Leica Microsystems, Wetzlar, Germany). Focus variation microscopy was also used to characterize 3D morphology of the cuts (InfiniteFocus from Alicona Imaging GmbH, Graz, Austria). The acquisitions were carried out with a ring light source and 10X magnification. With this configuration $0.46 \mu \mathrm{m}$ vertical and $3.91 \mu \mathrm{m}$ horizontal resolutions were achieved. After acquisitions, surface offset and inclinations were removed with the dedicated software (Alicona IF MeasureSuite).

\subsection{Experimental plan}

The experimental study consisted of different phases, as depicted in the flow chart in Fig. 3. In the first stage the technological feasibility zones were defined for the different material-laser combinations. All combinations were tested to determine the process limit lines, which define the highest cutting speed $\left(\mathrm{v}_{\mathrm{cut}}\right)$ admissible for a given material with the set laser parameters. As a matter of fact, a criterion to define the acceptability of the cut was required beforehand. In laser remote cutting with pulsed sources, the cut evolves from blind groves (Fig. 4.a) to partial cut (Fig. 4.b) before reaching a complete cut (Fig. 4.c) where the kerf is free of any uncut portions. Within this work, only complete cuts free of uncut sections were defined to be acceptable. This fact is essentially important to avoid short-circuiting in the manufactured battery. Due to the different characteristics of the two 
laser systems two different processing strategies were adopted. For the 1064 nm, 250 ns system both average power $\left(\mathrm{P}_{\text {avg }}\right)$ and pulse repetition rate (PRR) were varied. Thus, the study involved the variation of pulse energy, because different PRR levels with the same $\mathrm{P}_{\text {avg }}$ generate different pulse energy levels according to:

$\mathrm{P}_{\mathrm{avg}}=\mathrm{E} \cdot \mathrm{PRR}$

For a fixed $\mathrm{P}_{\mathrm{avg}}$ and PRR combination, cutting speed was varied starting from the maximum achievable value (36 $\mathrm{m} / \mathrm{min}$ ) and lowered with by steps of $3 \mathrm{~m} / \mathrm{min}$ until a complete cut was achieved. The maximum cutting speed that generated an acceptable cut was fixed as $\mathrm{v}_{\text {cut }}$.

On the other hand, the $532 \mathrm{~nm}, 1 \mathrm{~ns}$ system was operated at highest energy level due to limited energy content. Only PRR was varied to achieve different $\mathrm{P}_{\text {avg }}$ levels. Scan speed was varied starting from the maximum achievable value $(36 \mathrm{~m} / \mathrm{min})$ and lowered with by steps of $0.1 \mathrm{~m} / \mathrm{min}$ until a complete cut was achieved. For both of the laser systems $10 \mathrm{~mm}$ long scans with a single pass were made. Table 2 summarizes the varied parameter ranges in the remote cutting study with the two laser systems.

In the second phase the cut quality was evaluated regarding the clearance of the cut electrodes separately for the two laser systems. In the case of $1064 \mathrm{~nm}, 250 \mathrm{~ns}$ system due to the existence of technological feasibility and no cut zones an experimental design considering the whole parameter range would fail to produce acceptable cuts at all times. Therefore, an experimental study inside the technological feasibility zone was conducted. Instead of using fixed variables, the experimental plan was parameterized to fit within the technological zone of different materials. The average power levels were chosen as maximum average power $\left(\mathrm{P}_{\text {avg,max }}\right)$ as the high level, half the maximum average power $\left(1 / 2 \cdot \mathrm{P}_{\text {avg,max }}\right)$ as the low level, three quarters of maximum average power $\left(3 / 4 \cdot \mathrm{P}_{\text {avg,max }}\right)$ as the medium level. Similarly, the highest scan speed corresponded to the one belonging to the lowest average power level. This scan speed was called limit cutting speed ( $\left.\mathrm{v}_{\text {cut,limit }}\right)$ and constituted the high level of the scan speed in the experimental design. The low and middle points were set as one third limit cutting speed $\left(1 / 3 \cdot v_{\text {cut,limit }}\right)$ and two thirds limit cutting speed $\left(2 / 3 \cdot v_{\text {cut,limit }}\right)$ respectively. The experimental design is schematized in Fig. 5. This experimental plan was applied only with 50 and $80 \mathrm{kHz}$ PRR levels of the $1064 \mathrm{~nm}, 250 \mathrm{~ns}$ laser 
system, because below $50 \mathrm{kHz}$ the laser could not provide the power levels required in the experimental plan. Again, $10 \mathrm{~mm}$ long scans with a single pass were made. Clearance was measured on top side the cut kerf for both the cuts realized in the first and second experimental phases, resulting in an analysis made with $\mathrm{P}_{\mathrm{avg}}, \mathrm{v}$, and PRR as the input variables. A regression model was sought at the end of the experimental runs mixing measured clearances in both of the experimental sections. Separate models for anode and cathode clearances were fit using 36 experimental points with 2 measurements on both sides of the kerf.

On the other hand, the $532 \mathrm{~nm}, 1 \mathrm{~ns}$ system was evaluated only over the experimental points generated in the first phase. This decision was based on the fact that the system generated low average power output and the productivity was already low. On the other hand, the potentiality of the improvement of the cut quality could be visible already in the highest productivity available to this system.

In the final stage a technological assessment was made based on the quality and productivity performances of the material-laser system couples. Based on this assessment process selection and forecasts regarding the possible improvements were made.

\section{Results and discussion}

\subsection{Technological feasibility zones}

In Fig. 6.a the results of the cutting speed of anode and cathode as a function of processing parameters using the $1064 \mathrm{~nm}, 250 \mathrm{~ns}$ system is reported. For both materials the maximum cutting speed achievable was $30 \mathrm{~m} / \mathrm{min}$, with the maximum laser power. It can be observed that for both anode and cathode the effect of PRR over the achievable cutting speed is negligible. For $P R R=50 \mathrm{kHz}$ and $\mathrm{PRR}=80 \mathrm{kHz}$ the cutting speeds are very similar for as a function of average power. More interestingly, the linear trend is continued by the average power levels belonging to $\mathrm{PRR}=20 \mathrm{kHz}$. This fact points out that the processing depth is predominantly governed by the sum of energy deposited over time. As expressed in Eq.(1), this definition corresponds to average power. The linear regression model fitted to anode and cathode cutting speeds with $\mathrm{P}_{\text {avg }}$ as the single independent variable 
represents the linear trend over the whole range as depicted by the high $\mathrm{R}^{2}$ values. The slopes of the two regression lines appear to be very similar, with cathode material having a slightly higher slope. This can be interpreted that for higher average laser powers, anode material is likely to be cut faster than the cathode.

Fig. 6.b depicts the cutting speeds achievable with the $532 \mathrm{~nm}, 1 \mathrm{~ns}$ system for anode and cathode. Although the processing strategy involved the change of the PRR with fixed E a cleaner linear trend is visible for both materials. This observation is coherent with the previous consideration regarding the $\mathrm{P}_{\text {avg }}$ being the dominant factor over the cut depth. However, with this laser system the cutting speeds vary significantly as $2.4 \mathrm{~m} / \mathrm{min}$ and $3.18 \mathrm{~m} / \mathrm{min}$ have been achieve for anode and cathode respectively. The slopes of the regression lines depict a more pronounced difference between the two materials. Cathode is expected to be cut much faster with higher power input compared to the anode.

In both cases the linear relationship between the average power and cutting speed is coherent with the lumped heat capacity model used to estimate the cutting speed [24]. This model is highly approximate, assumes continuous wave emission and isotropy in material properties. For a given material the model approximates maximum cutting speed as power balance to vaporize a unit volume as:

$\mathrm{v}_{\text {cut }}=\frac{A \cdot P}{\mathrm{~d}_{\mathrm{o}} \cdot \mathrm{t} \cdot \rho \cdot\left(\mathrm{c}_{\mathrm{p}} \cdot\left[\mathrm{T}_{\mathrm{v}}-\mathrm{T}_{0}\right]+\mathrm{L}\right)}$

As the cut material in this case is a composite, it is not possible to estimate the material physical properties by singular coefficients. However the expression can be simplified as:

$\mathrm{v}_{\text {cut }}=\mathrm{C} \cdot \mathrm{P}_{\mathrm{avg}}$

The $\mathrm{C}$ parameter corresponds to the slope of the regression model and aggregates all the material related parameters. The slight differences in the observed slope values for anode and cathode cut with same laser source can be therefore explained as a counterbalance of differences in physical properties, reflectivity and thickness of the two materials. The $\mathrm{C}$ parameter therefore can be interpreted as a machinability indicator, where higher $\mathrm{C}$ values correspond to better machinability. According to Eq.(2) machinability depends not only on the material 
properties but also the used laser source. The comparison between the different $\mathrm{C}$ values show that the $1064 \mathrm{~nm}$, $250 \mathrm{~ns}$ improves the machinability of both the materials due to high pulse energy content and longer thermal pulses.

\subsection{Clearance and cut quality}

The measurements showed that for the $1064 \mathrm{~nm}, 250 \mathrm{~ns}$ system the clearance of anode varied between $34-52 \mu \mathrm{m}$ on the limit line and 34-98 $\mu \mathrm{m}$ within the experimental points below the limit line. For cathode the measurements showed clearance between $34-49 \mu \mathrm{m}$ on the limit line and 37-77 $\mu \mathrm{m}$ within the experimental points below the limit line. As a matter of fact the measurement put into evidence that the process should be applied on the limit line in order to achieve reduced clearance. The fitted regression models also confirmed this observation. It was observed that transformation of average power and scan speed as $(\mathrm{v}[\mathrm{m} / \mathrm{min}])^{-1}$ and $\exp \left(\mathrm{P}_{\text {avg }}\right.$ $[\mathrm{kW}])$ were adequate for fitting models for both of the materials. Moreover, the models did not include intercept.

For anode material, the regression model constituted of all the parameters and their interactions. The regression equation was found to be:

$$
\begin{aligned}
& \mathrm{w}_{\mathrm{c}, \text { anode }}[\mu \mathrm{m}]=-7265.95 \cdot(\mathrm{v}[\mathrm{m} / \mathrm{min}])^{-1}+43.70 \cdot \exp \left(\mathrm{P}_{\mathrm{avg}}[\mathrm{kW}]\right)-5.30 \cdot \mathrm{PRR}[\mathrm{kHz}]+7130.77 \cdot \\
& (\mathrm{v}[\mathrm{m} / \mathrm{min}])^{-1} \cdot \exp \left(\mathrm{P}_{\mathrm{avg}}[\mathrm{kW}]\right)+92.96 \cdot(\mathrm{v}[\mathrm{m} / \mathrm{min}])^{-1} \cdot \operatorname{PRR}[\mathrm{kHz}]+4.84 \cdot \exp \left(\mathrm{P}_{\mathrm{avg}}[\mathrm{kW}]\right) \cdot \\
& \mathrm{PRR}[\mathrm{kHz}]-89.60 \cdot(\mathrm{v}[\mathrm{m} / \mathrm{min}])^{-1} \cdot \exp \left(\mathrm{P}_{\mathrm{avg}}[\mathrm{kW}]\right) \cdot \operatorname{PRR}[\mathrm{kHz}]
\end{aligned}
$$

The model fit the experimental data well as depicted by the high $\mathrm{R}_{\text {adj }}^{2}$ value at $99.1 \%$. Among the parameters the most influential ones appear to be $(\mathrm{v}[\mathrm{m} / \mathrm{min}])^{-1}$, $\exp \left(\mathrm{P}_{\mathrm{avg}}[\mathrm{kW}]\right)$ and their interaction. The regression equation can be better interpreted through the plots shown in Fig. 7. The plots show clearance contour plots as a function of scan speed and average output power within the technological feasibility limits. It can be observed that the smallest clearance $\mathrm{w}_{\mathrm{c}}$, anode $=30.8 \mu \mathrm{m}$ is achievable by the reduction of all the three laser parameters $\left(\mathrm{P}_{\mathrm{avg}}=8.78 \mathrm{~W}\right.$, $\mathrm{PRR}=20 \mathrm{kHz}, \mathrm{v}=3 \mathrm{~m} / \mathrm{min}$ ). The clearance at highest productivity in this case was $41 \mu \mathrm{m}$ with $\mathrm{P}_{\text {avg }} 52.2 \mathrm{~W}$, 
$\mathrm{PRR}=50 \mathrm{kHz}, \mathrm{v}=30 \mathrm{~m} / \mathrm{min}$. The plots show that going towards more energetic conditions by reducing scan speed and increasing average power, clearance increased. This can be attributed to the fact that the contrast in the machinability of the graphite coating and $\mathrm{Cu}$ sheet. Prolonged exposure to the laser beam causes more graphite removal than $\mathrm{Cu}$. The high thermal conductivity of $\mathrm{Cu}$ would also allow the absorbed heat to dissipate into graphite layer facilitating its removal. At this point, the top graphite layer is exposed to the ablation plume more, which may contribute as a heat source.

For cathode material, the regression model constituted of only $(\mathrm{v}[\mathrm{m} / \mathrm{min}])^{-1}$, $\exp \left(\mathrm{P}_{\mathrm{avg}}[\mathrm{kW}]\right)$ and their interaction:

$\mathrm{w}_{\mathrm{c}, \text { cathode }}[\mu \mathrm{m}]=-3291.90 \cdot(\mathrm{v}[\mathrm{m} / \mathrm{min}])^{-1}+36.84 \cdot \exp \left(\mathrm{P}_{\mathrm{avg}}[\mathrm{kW}]\right)+3248.88 \cdot(\mathrm{v}[\mathrm{m} / \mathrm{min}])^{-1}$. $\exp \left(\mathrm{P}_{\mathrm{avg}}[\mathrm{kW}]\right)$

The model fits well the experimental data also in this case with a high $\mathrm{R}^{2}$ adj value at $99.26 \%$. The absence of PRR and its interactions show that the material is less prone to thermal cycle changes, which is in agreement with the observations in Ref [21]. Fig. 8 reports the plots of the regression model for $20 \mathrm{kHz}$ and $50-80 \mathrm{kHz}$ ranges with the technological feasibility limits. Similar to anode, the smallest clearance was achievable with lowest average power and cutting speed available $\left(\mathrm{P}_{\mathrm{avg}}=8.78 \mathrm{~W}, \mathrm{v}=3 \mathrm{~m} / \mathrm{min}\right)$. Although it was found to be a nonsignificant parameter, the pulse repetition rate was consecutively at the lowest possible level (PRR=20 kHz) to achieve the lowest average power.

Fig. 9 shows the evolution of clearance width as a function of kerf width over the experimental points on the limit line for the $1064 \mathrm{~nm}, 250 \mathrm{~ns}$ system. The increasing values correspond to increasing average power levels intrinsically. The lumped heat capacity model expressed in Eq.2 considers constant kerf width, while the P/v proportion is kept constant, which is not the present case. Moreover, the plot shows that clearance becomes larger as the kerf expands. This is due to the differences in the machining rates of the coating and middle layers in the composite materials. As the previous regression analysis depicted, below the limit line no margin of improvement exists; but also on the limit line the more energetic conditions result in a larger clearance extent 
due to more remarked difference of material removal rate. Therefore for both anode and cathode lowest power levels at highest limit cutting speeds should be employed to minimize the clearance.

The clearance measurements on anode and cathode with the 532 nm, 1 ns system are depicted in Fig.10. The cuts were achieved with the same power levels for both of the materials, however corresponding scan speeds differed as reported previously. It can be seen that the cathode material shows a logarithmic increase in the clearance as a function of average power. The lowest clearance was found to be $\mathrm{w}_{\mathrm{c}, \text { anode }}=19.5 \mu \mathrm{m}$ and was obtained with the lowest average power and scan speed $\left(\mathrm{P}_{\mathrm{avg}}=0.97 \mathrm{~W}, \mathrm{PRR}=50 \mathrm{kHz}, \mathrm{v}=0.18 \mathrm{~m} / \mathrm{min}\right)$. With increasing power clearance became comparable to the values belonging to the $1064 \mathrm{~nm}, 250$ system. The reduction of clearance on anode can be attributed to the low power levels used and higher beam intensity allowed by the smaller beam. The molten $\mathrm{Cu}$ fraction can be reduced by improved absorption and reduced thermal interaction. But the generated plume may be still strong enough to contribute to mechanically etch the graphite layer. As a matter of fact the observed graphite morphology was much more porous compared to cathode. The high pressure front generated with the ablation plume may be high enough to help material removal by mechanical interaction.

On the other hand, clearance could be completely removed on cathode material. The cut kerf showed no clearance within the applied power range. This can be attributed to an improvement in the laser beam absorption of Al. Moreover, short pulse duration allows less heat dissipation into the material. Resulting interaction with the material remains in a confined region.

Fig. 11 shows the cut quality of the smallest clearance achieved on all material-laser combinations. In the optical microscopy images found in the insets, the revealed middle layer of the sandwich materials can be seen. Moving from $1064 \mathrm{~nm}, 250 \mathrm{~ns}$ system to $532 \mathrm{~nm}, 1 \mathrm{~ns}$ system the change in the clearance extent is remarkable. The 3D contours shown in pseudo colours indicate that the cuts generated with the $1064 \mathrm{~nm}, 250 \mathrm{~ns}$ system are characterized by large kerf and stepped reduction from the top to the bottom layer. In contrast the cuts generated with the $532 \mathrm{~nm}, 1 \mathrm{~ns}$ system have much smaller kerf and a smoother reduction in height with a tapered shape. 


\subsection{Technological assessment}

Table 3 gathers the principal results coming from the study showing the highest quality and highest productivity conditions. The results show that the $1064 \mathrm{~nm}, 250 \mathrm{~ns}$ system is already capable of reaching required productivity $\left(\mathrm{v}_{\mathrm{cut}}=30 \mathrm{~m} / \mathrm{min}\right)$ with the maximum available power $\left(\mathrm{P}_{\mathrm{avg}}=54 \mathrm{~W}\right)$ on both anode and cathode with clearance extent larger than the acceptance level. In either case the clearance could not be lowered below $30 \mu \mathrm{m}$. If such clearance values can be tolerated via adjustments in the component design, the process can be adapted to the industrial production. The $532 \mathrm{~nm}, 1 \mathrm{~ns}$ system stays much lower than the required productivity level, however shows promise for the quality aspect. For both anode and cathode required clearance level $\left(\mathrm{w}_{\mathrm{c}}<20 \mu \mathrm{m}\right)$ was achieved, whereas for cathode it could be completely eliminated. If the calculated regression models should be used to roughly estimate the required power to remotely cut anode and cathode with this system the corresponding levels would be $71 \mathrm{~W}$ and $66 \mathrm{~W}$ respectively. It is not expected to provide significant improvement of clearance on anode compared to the $1064 \mathrm{~nm}, 250 \mathrm{~ns}$ system. However, the cut quality of cathode can be maintained with high productivity, with the increase of average power with $532 \mathrm{~nm}$ wavelength and reduced pulse duration. The average power can be increased through higher pulse repetition rates and/or higher pulse energies. The effect of increased average power should be however evaluated, since degrading effects such as plasma shielding and heat build-up can occur due to higher pulse energy and repetition rate.

\section{Conclusions}

This work reports laser remote cutting of Li-ion battery cathodes using two pulsed fibre laser systems operating in IR and green wavelengths. It has been confirmed that the pulsed fibre laser technology is a viable option for the remote cutting of the thin composite sheets. In particular the IR system, which was characterized by $1064 \mathrm{~nm}$ wavelength and $250 \mathrm{~ns}$ pulse duration allowed high productivity reaching cutting speeds of $30 \mathrm{~m} / \mathrm{min}$ for both of the electrode materials. One of the most relevant issues regarding the cut quality, the clearance was investigated throughout designed experiments with the aim to minimize it on both materials. Regression models were fit for 
different laser-material combinations. It has been observed that with the IR system clearance cannot be reduced any more than $30 \mu \mathrm{m}$ for both of the materials and the smallest clearance could be achievable with low productivity conditions. The green wavelength system showed much lower productivity, however significant improvement in the cut quality was observed. Anode clearance could be lowered down to $19.5 \mu \mathrm{m}$, whereas cathode clearance could be completely eliminated. The improvement was attributed to the low energy input in reduced pulse duration for the anode material. On the other hand, the reduction in the absorption contrast is expected to improve the quality for the cutting of cathode. To match the productivity requirements, $71 \mathrm{~W}$ and 66 $\mathrm{W}$ are estimated average power levels required for anode and cathode respectively. Although these estimates are rough, they indicate the feasibility of such operation, since pulsed green lasers operating with such power levels are commercially available. The increase in average power can be achieved by increasing energy content, increasing pulse repetition rate or increasing the pulse duration. However, the power sizing with any of such options would require a validation before full integration to the industrial scheme.

The present work showed a possible pathway for optimization of cutting conditions on remote cutting of multilayer thin sheets. Such approach can be extended to other anode and cathode materials or other components made of multi-layer thin sheets. Before selecting candidate laser sources material physical and optical characteristics should be assessed. For different optical characteristics wavelength choice becomes crucial, whereas for different thermal properties pulse duration becomes more important. For material combinations showing similar optical and thermal properties continuous wave sources are convenient as they provide high productivity. On the other side, if both the optical and thermal properties differ ultra-short pulsed lasers appear to be a relevant solution. These sources compensate the differences in absorption and avoid thermal interaction by interacting with the material in a very short time scale. 


\section{References}

[1] Peterson S, Whitacre J, Apt J (2011) Net air emissions from electric vehicles: The effect of carbon price and charging strategies. Environ Sci Technol 45(5):1792-1797

[2] Winter M, Brodd RJ (2004) What Are Batteries, Fuel Cells, and Supercapacitors? Chem Rev 104: 42454269.

[3] Goodenough JB, Kim Y (2010) Challenges for Rechargeable Li Batteries. Chem. Mater. 22(3): 587-603

[4] Scrosati B, Garche J (2010) Lithium batteries: Status, prospects and future. J Power Sources 165(1):2419-2430

[5] Patil A, Patil V, Shin DW, Choi J-W, Paik D-S, Yoon S-J (2008) Issue and challenges facing rechargeable thin film lithium batteries, Materials Research Bulletin 43(8-9):1913-1942

[6] Lütke M, Mahrle A, Himmer T, Morgenthal L, Beyer E (2008) Remote-cutting - a smart solution using the advantages of high brightness lasers, In Proceedings of $27^{\text {th }}$ International Congress on Applications of Lasers \& Electro-Optics ICALEO, 695-702

[7] Zaeh MF, Moesla J, Musiol J, Oefele F (2010) Material Processing with Remote Technology Revolution or Evolution? Phys Procedia 5(A):19-33

[8] Mahrle A, Lütke M, Beyer E (2010) Fibre laser cutting: beam absorption characteristics and gas-free remote cutting. Proc Inst Mech Eng C J Mech Eng Sci 224(5):1007-1018

[9] Wagner A, Lütke M, Wetzig A, Eng LM (2013) Laser remote-fusion cutting with solid-state lasers. J Laser Appl 25(5): 052004-1- 052004-8

[10] Jung K-W, Kawahito Y, Katayama S (2012), Ultra-high speed disk laser cutting of carbon fiber reinforced plastics, J Laser Appl 24(1): 012007-1 - 012007-8

[11] Hellmann R, Adelmann B (2013), Process optimization of laser fusion cutting of multilayer stacks of electrical sheets, Int J Adv Manuf Technol 68:2693-2701

[12] Fürst A, Klotzbach A, Hühne S, Hauptmann J, Beyera E (2013), Phys Procedia 41: 389 - 398

[13] Fuchs AN, Schoeberl M, Tremmer J, Zaeh MF (2013) Laser Cutting of Carbon Fiber Fabrics. Phys Procedia 41:372-380 
[14] Lütke M, Hauptmann J, Wetzig A, Beyer E (2012) Energetic efficiency of remote cutting in comparison to conventional fusion cutting. J Laser Appl 24:022007-1-022007-7

[15] Hock K, Adelmann B, Hellmann R (2012) Comparative study of remote fiber laser and water-jet guided laser cutting of thin metal sheets. Phys Procedia 39: 225-231

[16] Finger J, Weinand M, Wortmann D (2013), Ablation and cutting of carbon-fiber reinforced plastics using picosecond pulsed laser radiation with high average power, J Laser Appl 25(4): 042007-1 $-042007-5$

[17] Wang XC, Zheng HY, Chu PL, Tan JL, Teh KM, Liu T, Ang BCY, Tay GH (2010) High quality femtosecond laser cutting of alumina substrates. Opt Laser Eng 48(6): 657-663

[18] Muhammad N, Li L (2012) Underwater femtosecond laser micromachining of thin nitinol tubes for medical coronary stent manufacture. Appl Phys A107(4):849-861

[19] Luetke M, Franke V, Techel A, Himmer T, Klotzbach U, Wetzig A, Beyer E (2011) A Comparative Study on Cutting Electrodes for Batteries with Lasers. Phys Procedia 12B:286-291.

[20] Lee D, Patwa R, Herfurth H, Mazumder J (2012) Computational and experimental studies of laser cutting of the current collectors for lithium-ion batteries. J Power Sources 210:327- 338

[21] Lee D, Patwa R, Herfurth H, Mazumder J (2013) High speed remote laser cutting of electrodes for lithium-ion batteries: Anode. J Power Sources 240: 368-380

[22] Schmieder B (2012) Laser cutting of graphite anodes for automotive lithium-ion secondary batteries: investigations in the edge geometry and heat affected zone. In Proc. SPIE 8244, Laser-based Micro- and Nanopackaging and Assembly VI, 82440R; doi:10.1117/12.912767.

[23] Quintino L, Costa A, Miranda R, Yapp D, Kumar V, Kong CJ (2007) Welding with high power fiber lasers - A preliminary study. Mater Design 28(4):1231-1237 


\section{List of tables}

Table 1. General specifications of the used laser systems.

\begin{tabular}{lll}
\hline Brand and model & IPG YLP-1/100/50/50 & IPG YLPG-5 \\
Architecture & Fibre, Q-switched & Fibre, MOPA \\
Wavelength & $1064 \mathrm{~nm}$ & $532 \mathrm{~nm}$ \\
Max. average power & $54 \mathrm{~W}$ & $6 \mathrm{~W}$ \\
Pulse repetition rate & $20-80 \mathrm{kHz}$ & $20-300 \mathrm{kHz}$ \\
Max. pulse energy & $1.02 \mathrm{~mJ}$ & $0.02 \mathrm{~mJ}$ \\
Pulse duration & $250 \mathrm{~ns}$ & $1 \mathrm{~ns}$ \\
Polarization state & Random & Linear \\
M $^{2}$ & 1.7 & 1.12 \\
Collimated beam diameter & $5.9 \mathrm{~mm}$ & $3.5 \mathrm{~mm}$ \\
Focal length & $100 \mathrm{~mm}$ & $100 \mathrm{~mm}$ \\
Calculated diameter at focal point & $39 \mu \mathrm{m}$ & $22 \mu \mathrm{m}$ \\
\hline
\end{tabular}

Table 2. Varied parameter ranges for the two lasers employed in the technological feasibility study.

\begin{tabular}{lll}
\hline Laser type & $\lambda=1064 \mathrm{~nm} ; \tau=250 \mathrm{~ns}$ & $\lambda=532 \mathrm{~nm} ; \tau=1 \mathrm{~ns}$ \\
\hline $\mathrm{P}_{\text {avg }}$ & $10-50 \mathrm{~W}$ & $1-6 \mathrm{~W}$ \\
$\mathrm{PRR}$ & $20-80 \mathrm{kHz}$ & $50-300 \mathrm{kHz}$ \\
$\mathrm{E}$ & $0.25-1.02 \mathrm{~mJ}$ & $0.02 \mathrm{~mJ}$ \\
$\mathrm{v}$ & $9-360 \mathrm{~m} / \mathrm{min}$ & $0.18-30 \mathrm{~m} / \mathrm{min}$ \\
\hline
\end{tabular}


Table 3. Comparison of best quality and highest productivity conditions for the different material-laser system combinations.

\begin{tabular}{|c|c|c|c|c|c|c|c|}
\hline Condition & Material & Laser system & $\mathrm{P}_{\mathrm{avg}}$ & PRR & $\mathrm{v}_{\mathrm{c}}$ & $\mathrm{W}_{\mathrm{c}}$ & $\mathrm{w}_{\mathrm{k}}$ \\
\hline & & $1064 \mathrm{~nm}, 250 \mathrm{~ns}$ & $8.78 \mathrm{~W}$ & $20 \mathrm{kHz}$ & $3 \mathrm{~m} / \mathrm{min}$ & $33.8 \mu \mathrm{m}$ & $30.8 \mu \mathrm{m}$ \\
\hline & Anode & & & & & & \\
\hline & & $532 \mathrm{~nm}, 1 \mathrm{~ns}$ & $0.97 \mathrm{~W}$ & $50 \mathrm{kHz}$ & $0.18 \mathrm{~m} / \mathrm{min}$ & $19.5 \mu \mathrm{m}$ & $10.3 \mu \mathrm{m}$ \\
\hline \multicolumn{8}{|c|}{ Best quality } \\
\hline & & $1064 \mathrm{~nm}, 250 \mathrm{~ns}$ & $8.78 \mathrm{~W}$ & $20 \mathrm{kHz}$ & $4.5 \mathrm{~m} / \mathrm{min}$ & $33.7 \mu \mathrm{m}$ & $40 \mu \mathrm{m}$ \\
\hline \multicolumn{8}{|c|}{ Cathode } \\
\hline & & $532 \mathrm{~nm}, 1 \mathrm{~ns}$ & $5.79 \mathrm{~W}$ & $300 \mathrm{kHz}$ & $3.12 \mathrm{~m} / \mathrm{min}$ & $0 \mu \mathrm{m}$ & $<10 \mu \mathrm{m}$ \\
\hline & & $1064 \mathrm{~nm}, 250 \mathrm{~ns}$ & $52.2 \mathrm{~W}$ & $50 \mathrm{kHz}$ & $30 \mathrm{~m} / \mathrm{min}$ & $48.8 \mu \mathrm{m}$ & $41 \mu \mathrm{m}$ \\
\hline & Anode & & & & & & \\
\hline & & $532 \mathrm{~nm}, 1 \mathrm{~ns}$ & $5.79 \mathrm{~W}$ & $300 \mathrm{kHz}$ & $2.4 \mathrm{~m} / \mathrm{min}$ & $38 \mu \mathrm{m}$ & $12.3 \mu \mathrm{m}$ \\
\hline \multicolumn{8}{|c|}{ Highest productivity } \\
\hline & & $1064 \mathrm{~nm}, 250 \mathrm{~ns}$ & $53.3 \mathrm{~W}$ & $80 \mathrm{kHz}$ & $30 \mathrm{~m} / \mathrm{min}$ & $40 \mu \mathrm{m}$ & $40.3 \mu \mathrm{m}$ \\
\hline \multicolumn{8}{|c|}{ Cathode } \\
\hline & & $532 \mathrm{~nm}, 1 \mathrm{~ns}$ & $5.79 \mathrm{~W}$ & $300 \mathrm{kHz}$ & $4.5 \mathrm{~m} / \mathrm{min}$ & $0 \mu \mathrm{m}$ & $<10 \mu \mathrm{m}$ \\
\hline
\end{tabular}




\section{List of figures}

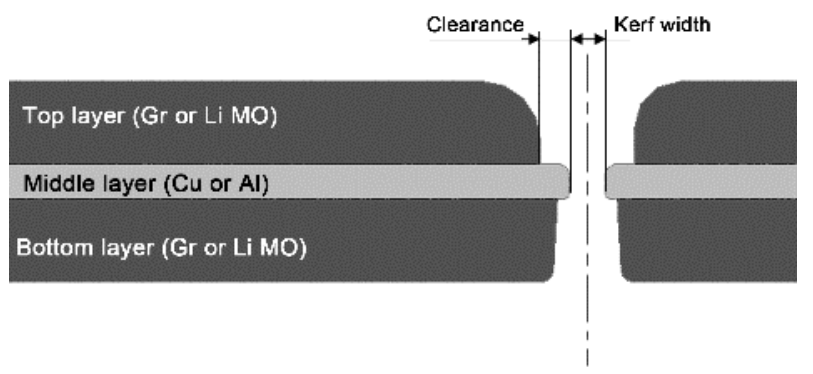

Figure 1. Schematic representation of a remote laser cut electrode cross section.

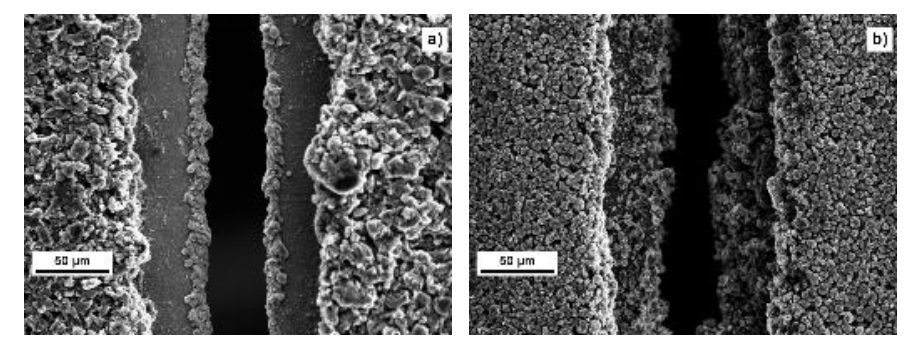

Figure 2. Example SEM images of laser cut (a) anode and (b) cathode showing the coating and middle layer material morphology. 


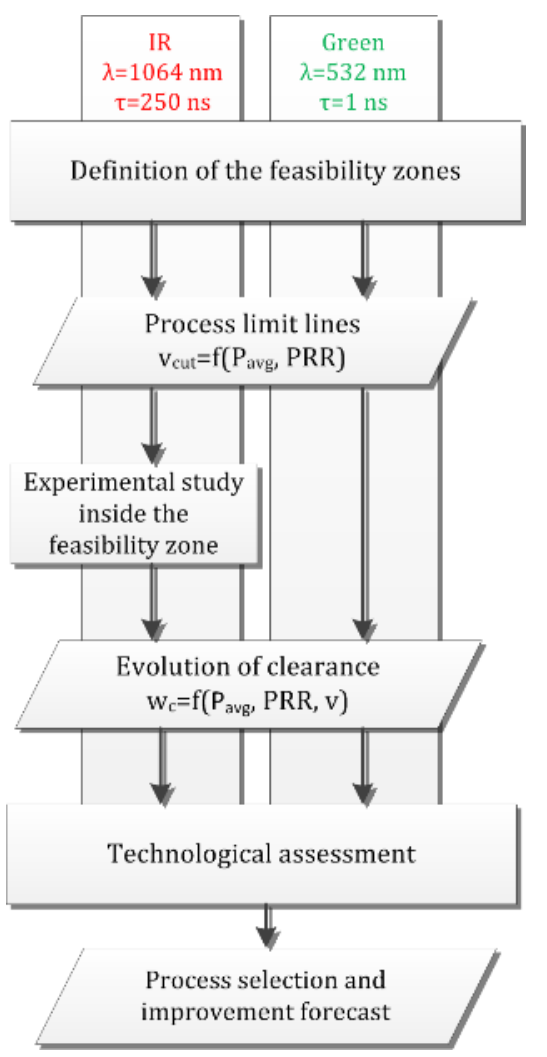

Figure 3. The flow chart of the experimental study depicting different phases and results deriving from them.
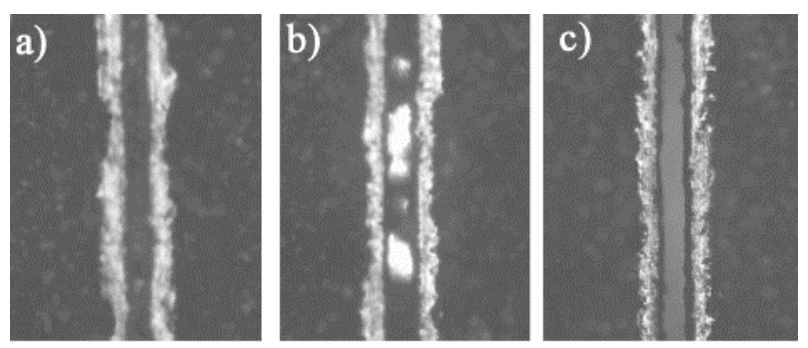

$250 \mu \mathrm{m}$

Figure 4. The evolution of remote laser cutting of electrodes (a) grove generation; (b) partial cut; (c) complete cut. 


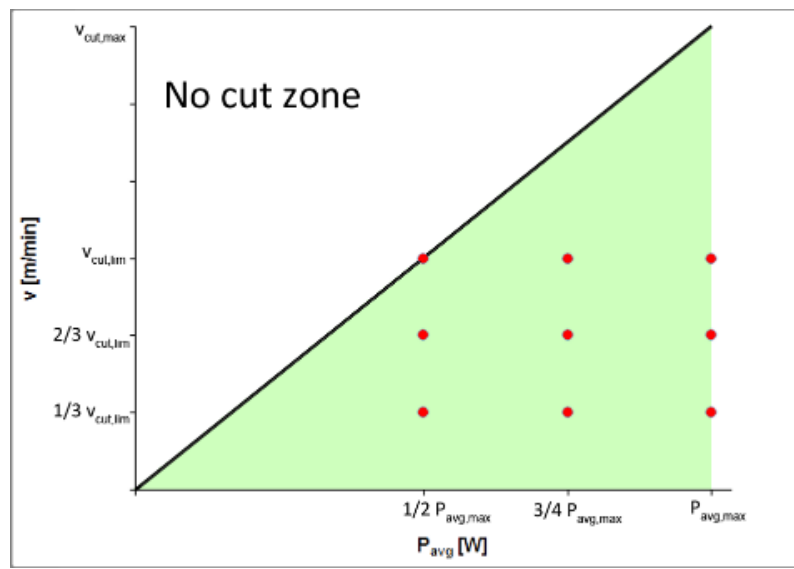

Figure 5. The experimental plan for clearance width investigation. The levels were parameterized to match different limit cutting speeds available for the anode and cathode materials.
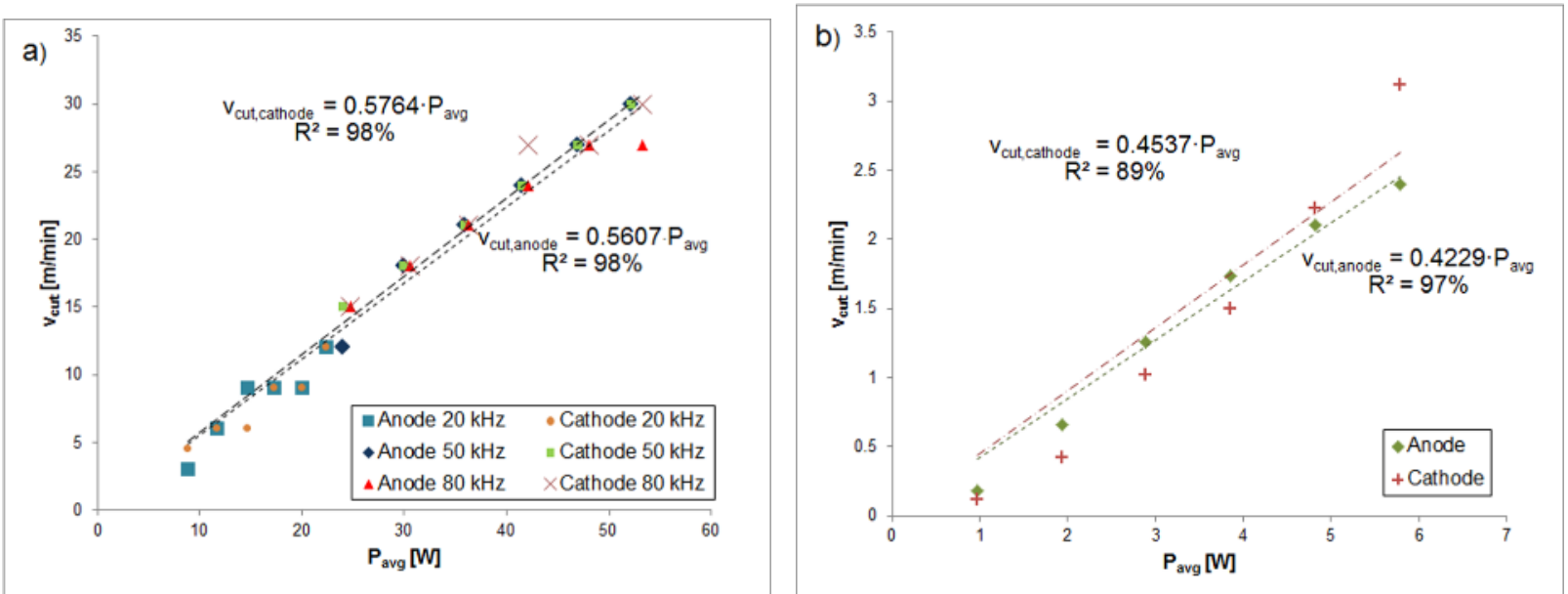

Figure 6. Cutting speed as a function of processing parameters belonging to anode and cathode with (a) 1064 nm, $250 \mathrm{~ns}$; (b) $532 \mathrm{~nm}, 1 \mathrm{~ns}$ pulsed system. 

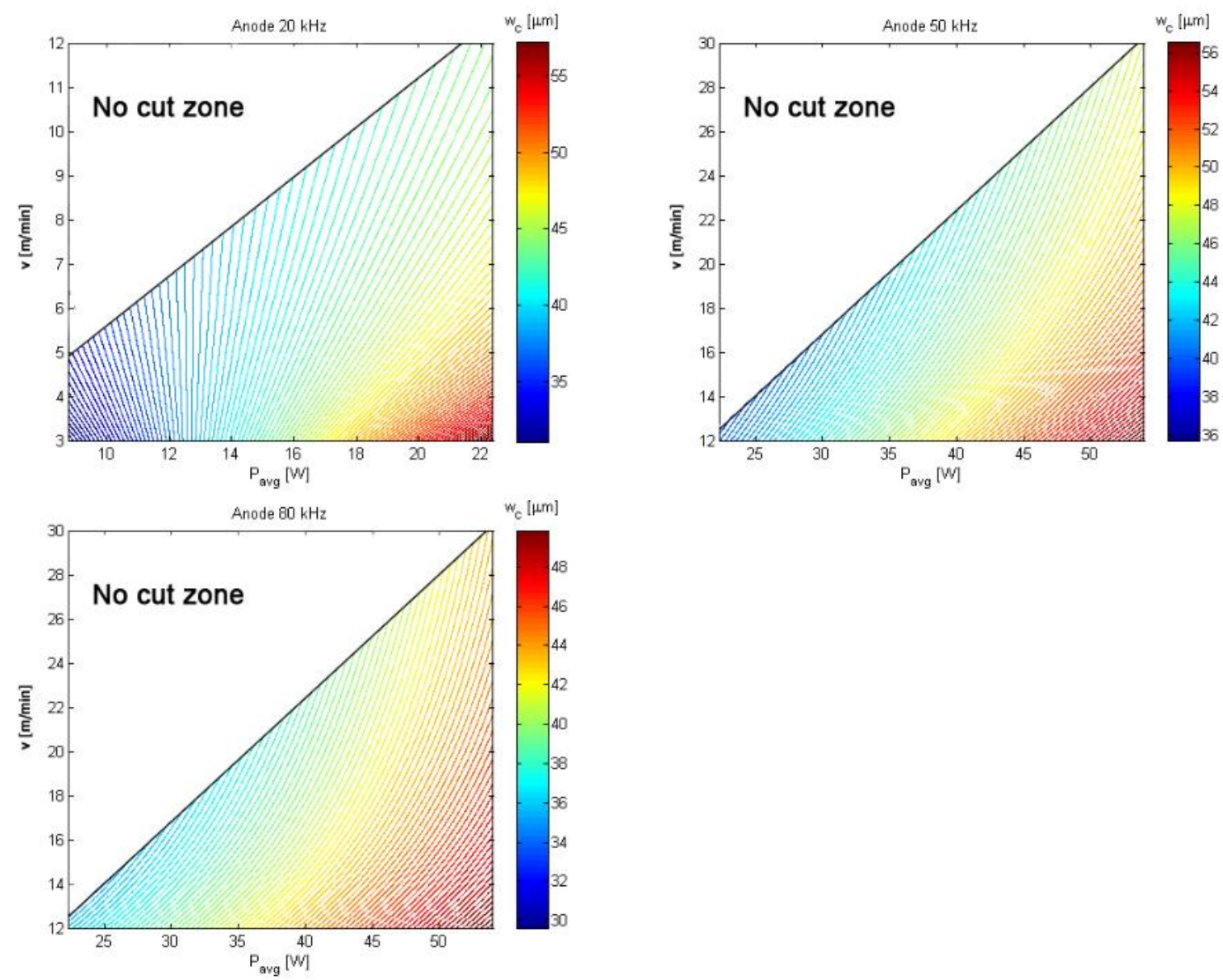

Figure 7. Regression model for clearance on anode ( $\mathrm{w}_{\mathrm{c}, \text { anode }}$ ) as a function of laser process parameters using 1064 nm, 250 ns laser system.
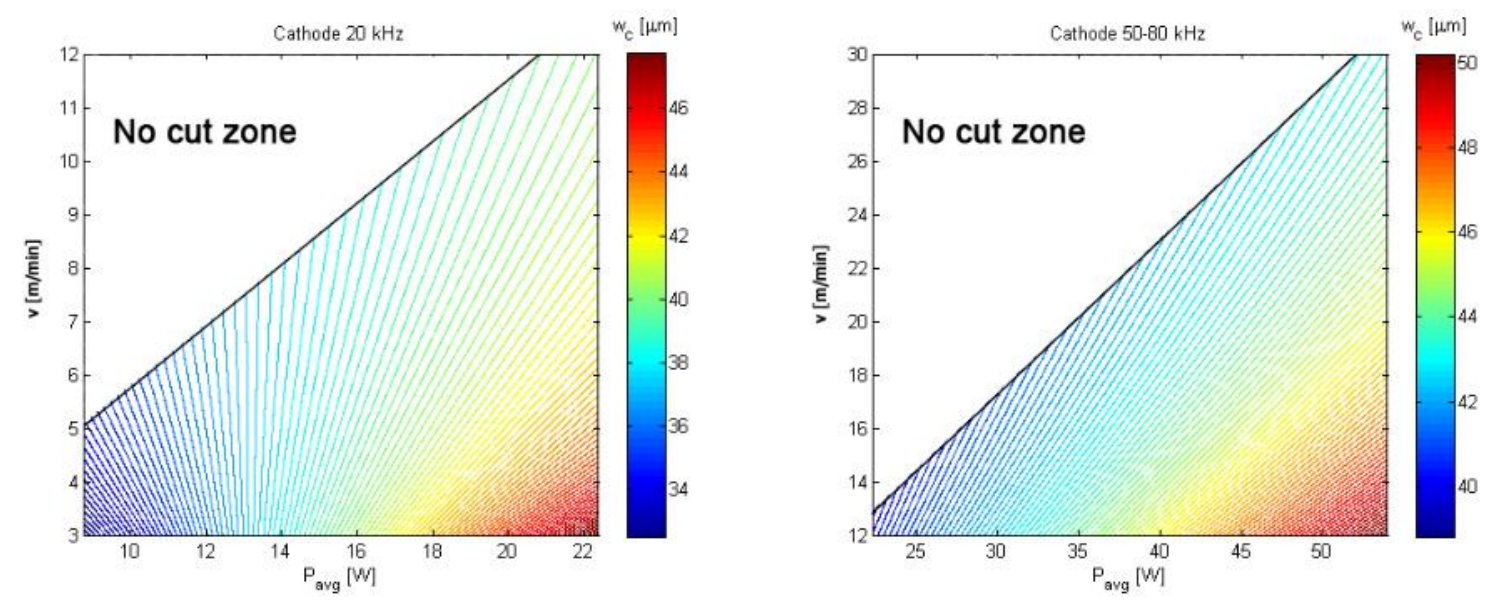

Figure 8. Regression model for clearance on cathode $\left(\mathrm{w}_{\mathrm{c}, \text { cathode }}\right)$ as a function of laser process parameters using $1064 \mathrm{~nm}, 250 \mathrm{~ns}$ laser system. 


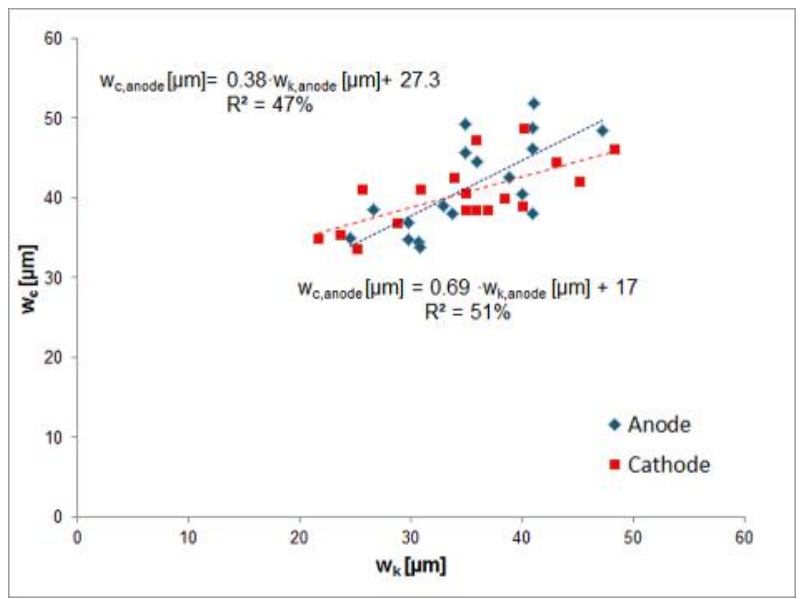

Figure 9. Clearance width as a function of kerf width obtained with the $1064 \mathrm{~nm}, 250 \mathrm{~ns}$ pulsed system.

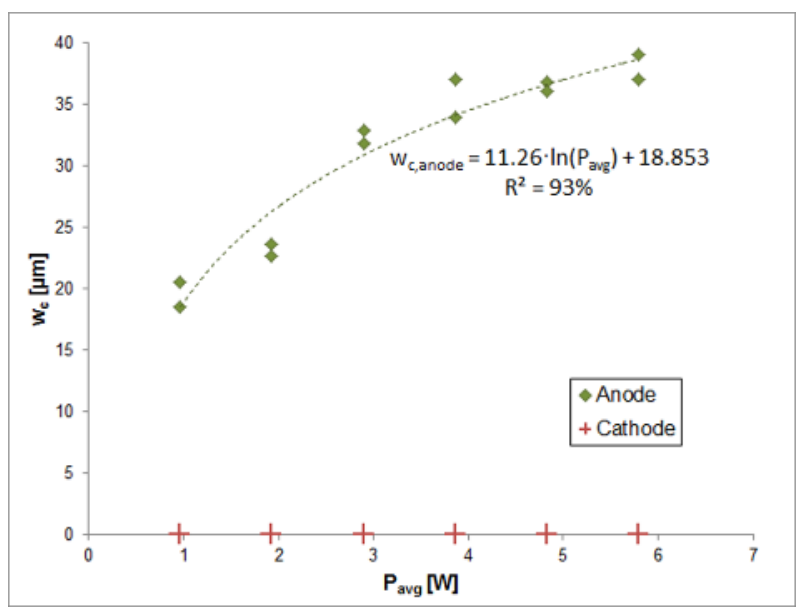

Figure 10. Regression model for clearance on anode $\left(\mathrm{w}_{\mathrm{c}, \text { anode }}\right)$ and measured values for clearance on cathode as a function of average laser power using $532 \mathrm{~nm}, 1 \mathrm{~ns}$ laser system. 


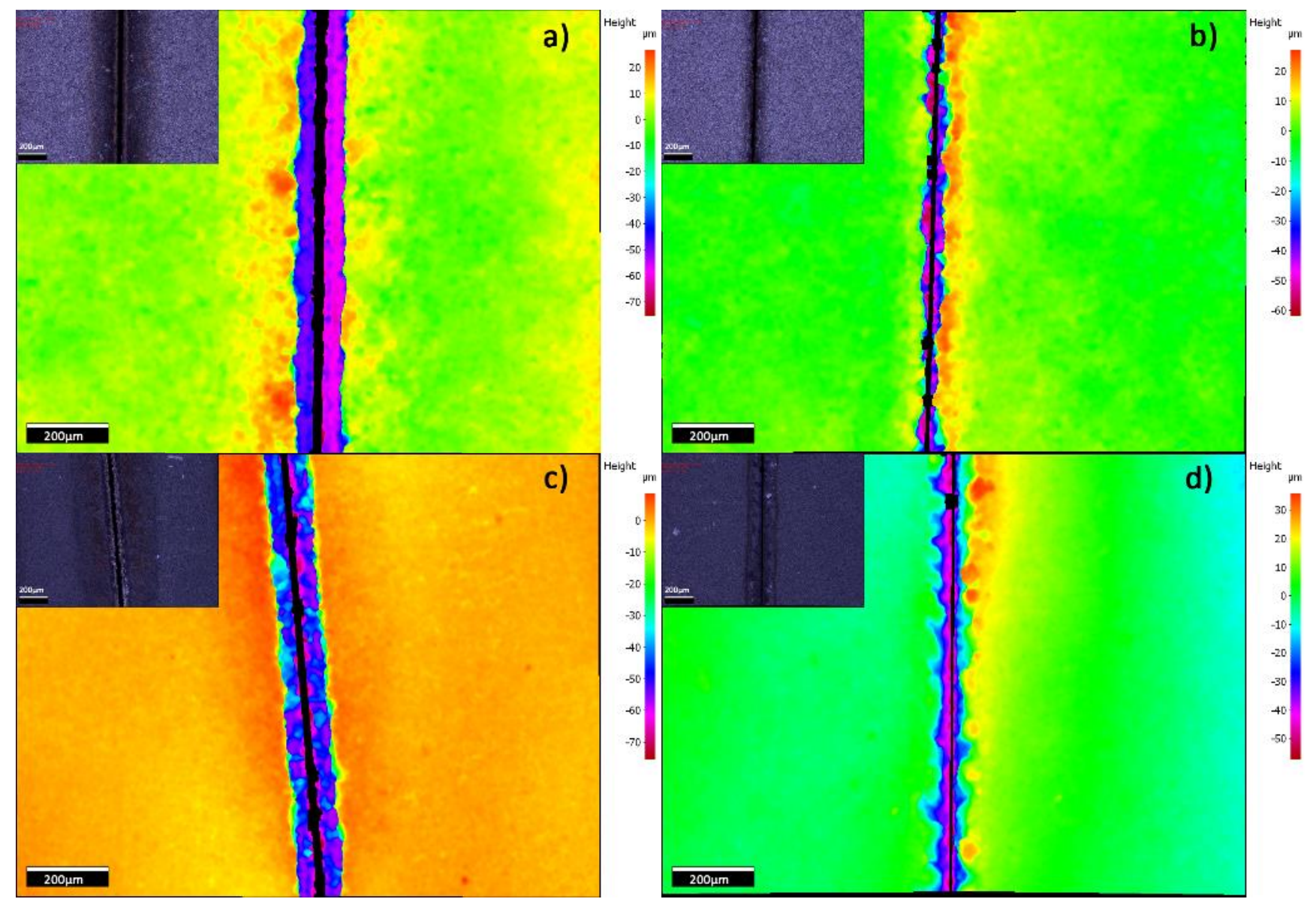

Figure 11. Optical and focus variation microscopy images belonging to achieved the best quality cuts: (a) anode cut with $1064 \mathrm{~nm}, 250 \mathrm{~ns}$ system, (b) anode cut with $532 \mathrm{~nm}, 1 \mathrm{~ns}$ system, (a) cathode cut with $532 \mathrm{~nm}, 1 \mathrm{~ns}$ system, (d) cathode cut with $532 \mathrm{~nm}, 1$ ns system 